\title{
Reforming Chinese Teacher Education: Findings from Training Program of Multiple-Subject Elementary School Teachers in Rural Northwestern China
}

\author{
Qingyun Wu, Mi Zhou, Hui Zhou \\ Qinghai Normal University, Qinghai, China \\ Wenfan Yan \\ University of Massachusetts, Boston, USA
}

\begin{abstract}
This research analyzed the lack of education practical competency and training curriculum in teacher education, redefined two core concepts: the educational practical competency and the multiple-subject elementary school teacher. Based on these analysis and definition, this study divided the educational practical competency into three level: basic competency, key competency, and external competency. According to the education practice theory, this study divides the multiple-subject elementary school teachers' educational practical competency into three parts: the practice to learning the practical wisdom, the practice to communicate with others, and the practice to reflect oneself. Through these review, this study designed three rounds of action research to find a practical way to promote students' educational practical competency, combined with the action research, the classroom observation, classroom interaction, and focused group interview. This cyclic openness process is renovated every round and reach the developing goal, at last finds some reformations of teacher education in rural Northwestern China.
\end{abstract}

Keywords: the multiple-subject elementary school teacher, educational practical abilities, action research

\section{Background of the Study}

With the development of economy and politics, people set a higher expectations on the development of education. Cultivating the multiple-subject teachers is a trend over the world and in order to meet the need of the educational reform, normal university undertakes the responsibility for cultivating the pre-service multiple-subject elementary school teachers. In 2001, the Chinese Ministry of Education issued "The Outline of National Basic Educational Curriculum Reform (proposed)," it pointed that primary school should set up more integrated curricula and based on the different subject curricula and activity curricula, they should increase science course, art course, and comprehensive practical activity courses. This outline also propose some new requirements for elementary school teachers. In 2014, the Chinese Ministry of Education issued "The

Qingyun Wu, professor, Department of Psychology, School of Education, Qinghai Normal University.

Mi Zhou, professor, Department of Psychology, School of Education, Qinghai Normal University.

Hui Zhou (Corresponding author), teaching assistant, Department of Psychology, School of Education, Qinghai Normal University.

Wenfan Yan, professor, Department of Leadership in Education, University of Massachusetts. 
Suggestions About How to Carrying the Training Plan of Excellent Teacher," this paper ruled that: "In order to cultivating the excellent elementary school teacher, normal university must cater to the actual demand of the primary school and focus on the survey of the training mode of multiple-subject elementary school teachers, and cultivating lots of excellent multiple-subject elementary school teachers who loves their career, possesses wide knowledge and comprehensive skills and is qualified to afford different subject teaching." Based on the facts that the geographic location in Western China is complexity and wide, many rural areas and pasturing areas in Qinghai province of China have lots of primary schools which contain only one or 10 students, the shortage of different subject teacher is the most serious problem. In order to save this problem, the Chinese Ministry of Education has been initiating a program "the Excellent Teacher Training Program of Primary and Secondary Schools.” Qinghai Normal University has conducted a research project which focused on the education of the pre-service multiple-subject elementary school teachers, especially for the five Northwestern provinces including the Tibetan area.

\section{Rationale and Purpose of the Study}

In 2011, the Ministry of Education in China issued "The National Teacher Education Curriculum Standard (proposed)," the teaching experience and practice part mentioned that students in normal university should develop the educational practical competency, they should go to elementary school at least every semester, observe the course, join in course activity and do some research, in this way, they can accumulate the teaching experience. These three steps are the basic rules to cultivating students' educational practical competency and form the practical teaching system under the reformation of normal university. In 2012, the Ministry of Education in China issued "The National Professional Standards for Primary and Secondary teachers," this standard emphasize the importance of the educational practical competency and the ability to combine the subject knowledge, the educational theory and the educational practice together. According to background and police, the pre-service multiple-subject elementary school teachers' teaching experience and development of practice competency is more important, because their learning way and practical competency will influence their teaching way in the future. This study summarize the literature review about the core concept: the educational practical competency and the multiple-subject elementary school teacher, and the related literacy and research, use the action researcher method to build a developmental training system which is suitable for western Chinese normal university students. What is more, group members also hope to use this system to training the in-service multiple-subject teacher.

\section{Literature Review}

According to all these policies and documents, the research group find that the lack of the educational practical competency of normal university student is the basic problem. Due to this deficiency, normal students cannot adapt the role of teacher and do not possess the professional competency after graduation.

Based on this problem, research group begin to search online and finished the literature review, they designed two topic: One is the multiple-subject elementary school teacher and the other is the cultivating of the educational practice competency of normal university students.

The research about the multiple-subject elementary school teacher divided into eight parts: the connotation and the key competency, the feasibility, the cultivating objective, the cultivating level, the cultivating mode, the construction of curriculum system, the cultivating methods, and the teaching material. 
The research about the cultivating of the educational practice competency of normal university students divided into three parts: the structure (Douglas, Gary, \& Jerry, 1982), the forming process and influencing factor (Fessler, 1985), and the cultivating process.

According to these research, group member found that the methods are singleness and just few people pay attention on the multiple-subject elementary school teachers' educational practice competency. Based on the review, we attempts to redefine the academic word: the educational practical competency and the multiple-subject elementary school teacher.

\section{Core Concept}

\section{Educational Practical Competency}

Organisation for Economic Co-operation and Development (OECD) pointed that key competency is an ability which can use and adjust all the mental social resources to satisfy the complicated need in a particular situation.

United Nations Educational, Scientific, and Cultural Organization (UNESCO) mentioned in rethinking education: Competencies are broader in scope. They refer to the ability to use knowledge- understood broadly as encompassing information, understanding, skills, values, and attitudes-in specific contexts and to meet demands. It identifies three main types of skills that all young people need-foundation, transferable, and technical and vocational skills — and the contexts in which they may be acquired.

Chinese members who joined the assessment and teaching of 21st century skills project summarized nine terms of key competency in three level which belongs to common field: higher-order cognition level: critical-thinking, problem-solving, and creativity and lifelong learning; self-development level: self-understanding and self-adjustment, life-plan and happiness; and social development level: communication and collaboration, leadership, cross-culture and international vision, civic responsibility, and social participation.

Hongqi Chu (2016) defined key competency as a practical ability, it is an integration of knowledge, skills and attitudes, it can be observed, teaching, learning, and measuring. Competency $=$ (Knowledge + Skill $)$ attitude, he considered that attitude is the core member of key competency.

According to all the definition, this study considered that the educational practical competency has its own internal basic support and external extension. The internal one is the basic competency: writing, speaking, and computer education. The essence is the core competency: persistent, critical thinking, respect, life-plan, self-adjustment, problem-solving, creativity, and lifelong learning. The external one is the wide competency: communication, listening, collaboration, leadership, cross-culture and international vision, civic responsibility, and social participation. These three level competency contains knowledge, skill, and attitude, and need to be trained during life-long study.

\section{The Multiple-Subject Elementary School Teacher}

Multiple-subject teacher is mentioned in The Report About Researching the Japanese Akita Elementary Math Education. This report said that Japanese elementary school teacher is the multiple-subject teacher. They can teach all the subjects in elementary school.

In 2014, the Chinese Ministry of Education issued "The Suggestions About How to Carrying the Training Plan of Excellent Teacher," this paper considered that multiple-subject teacher is not a teacher who can teach 
all the subjects, but the one who is well versed in integrating all the courses, and break the boundaries between different subjects. Their knowledge is rich, basic is solid, competency is high, ability is well, and adaptability is wide. They can know how to control the tension between profession and extensive well.

Jingfan Jiang (2016) considered that multiple-subject elementary school teacher is not the opposite idea with separate teacher, it is an independent idea. Their characteristics not only increasing the subjects but also considering the comprehensive capacity as the key competency and focusing on elementary school students' life-long development. Their main task is to develop children's perfect personality and good learning habits.

According to all the definition, this study defined the multiple-subject elementary school teacher as a new kind of teachers who possess the basic knowledge of teaching all the subjects in elementary school, undertake the task of curriculum development and researching in elementary school, regard comprehensive capacity as the key competency, evenly develop the professional knowledge, professional skill, and professional attitude and focus on children's whole life-long development and perfect personality. The core valuable purse is regard attitude as the support foundation, knowledge as the starting point, and competency as the developing goal.

\section{Theoretical Framework}

Manadu Sato (1951) is a Japanese educator, he defined "educational practice" in a new way and illustrate the relationship between theory and practice in education. He set up two new concept: theory in practice and practice in theory. His definition of curriculum — resume of learning experience; learning — a way to rebuild the meaning and relationship (a conversational practice); and subject-fragment knowledge transform into comprehensive learning, make group member to reflect the ultimate pursuit of education. His Learning Community Theory builds three dialogues through listening to each other in order to create mutual learning in learning reformation in education system, education community, and school development. He considered learning as a dialogue between object, dialogue between another, and dialogue between oneself. These definitions and theory serves as the theoretical framework for this study to classified the educational practice into three parts-learning the practical wisdom, communicate with others and reflecting oneself, to manage oneself and to develop oneself.

\section{Methods of Data Collection and Analysis}

This research lasted four years (from September 2014 to September 2018) and selected 83 students (45 Han students and 38 Tibetan students) majoring multiple-subject primary education in two classes. Based on the theoretical analyzing of the structure of educational practical competency, group members designed three rounds of action research to find a practical way to promote students' educational practical competency, combined with the classroom observation, classroom interaction and focused group interview. During every round, there are five steps: (a) planning; (b) action; (c) assessment; (d) reflective; and (e) re-planning. These steps guide each other together and every round connected together. This research is a cyclic openness process, the training system of educational practical ability in every round would be adjusted according to the result of reflective in the former round. As a result, this training system will be renovated every semester and reach the developing goal. 
Among these three action rounds, the core ideas of designing the practical curriculum are renovated and at last we designed seven courses, the specific process is in Tables 1 and 2. All these courses require students to form a learning community and cooperate with each other to finish every task. During the reflective part in every action round, group member firstly collected the feedback from teacher and students and interviewed every group member to get more suggestions. According to these feedback, group member reviews the training system and practice constantly.

Table 1

The Core Idea of Designing the Practical Curriculum

\begin{tabular}{|c|c|c|c|}
\hline Three different practice & Improve continuously & Improve continuously & Improve continuously \\
\hline $\begin{array}{l}\text { The practice to learning the } \\
\text { practical wisdom }\end{array}$ & $\begin{array}{ll}\text { Clear } \\
- & \text { Pay more attention on the } \\
& \text { skill } \\
\text { - } & \text { Training } \\
\text { - } & \text { Writing } \\
\text { - } & \text { Speaking } \\
\text { - } & \text { Computer education }\end{array}$ & Chaos & $\begin{array}{l}\text { Continuously define } \\
\text { - Teacher's self-growth } \\
\text { - } \quad \text { Persistent } \\
\text { - The communication for the } \\
\text { thinking result } \\
\text { - Computer based education }\end{array}$ \\
\hline $\begin{array}{l}\text { The practice to communicate } \\
\text { with others }\end{array}$ & Chaos & $\begin{array}{l}\text { Continuously define } \\
\text { - } \quad \begin{array}{l}\text { Learn to communicate } \\
\text { Diversified conversational } \\
\text { object }\end{array}\end{array}$ & $\begin{array}{l}\text { Define again } \\
\text { - } \quad \text { Learn to listening } \\
\text { Respect the difference, } \\
\text { respect the multiplex } \\
\text { heterogeneous } \\
\text { conversational mode }\end{array}$ \\
\hline The practice to reflect oneself & 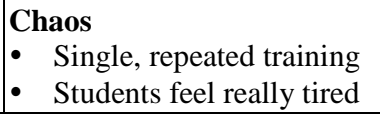 & $\begin{array}{l}\text { Continuously define } \\
\text { - General self-efficacy }\end{array}$ & $\begin{array}{l}\text { Define again } \\
\text { - } \begin{array}{l}\text { The construction of one's } \\
\text { real life }\end{array}\end{array}$ \\
\hline
\end{tabular}

Table 2

Three Rounds of Action Research

\begin{tabular}{|c|c|c|c|}
\hline Three differentpractice & First round & Second round & Third round \\
\hline $\begin{array}{l}\text { The practice to learning the } \\
\text { practical wisdom }\end{array}$ & $\begin{array}{l}\text { Daily training course } \\
\text { (writing and speaking) } \\
\quad \text { Educational technology } \\
\text { course } \\
\quad \text { The presentation of } \\
\text { teaching skill }\end{array}$ & $\begin{array}{l}\text { Daily training course+ } \\
\text { Internet communication } \\
\text { platform } \\
\text { E Educational technology } \\
\text { course+Educational appsusing } \\
\text { The presentation of } \\
\text { teaching skill +Design } \\
\text { micro-course online video }\end{array}$ & $\begin{array}{l}\text { Daily training course+ } \\
\text { Internet communication } \\
\text { platform } \\
\text { Educational technology } \\
\text { course+ Electronical mind map } \\
\quad \text { The presentation of } \\
\text { multiple-subject teaching skill } \\
\text { (two class combine together) } \\
\text { Thesis and book reading } \\
\text { course }\end{array}$ \\
\hline $\begin{array}{l}\text { The practice to communicate } \\
\text { with others }\end{array}$ & 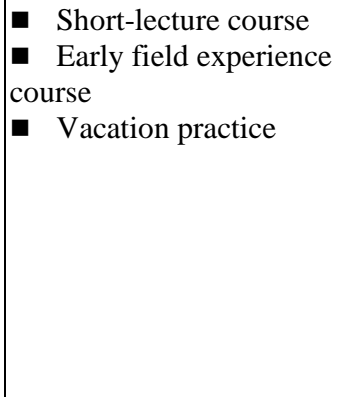 & $\begin{array}{l}\text { Short-lecture course } \\
\text { +Internet communication } \\
\text { platform } \\
\text { a Early field experience } \\
\text { course+ Internet } \\
\text { communication platform } \\
\text { a Vacation practice + Book } \\
\text { studying and reading } \\
\text { activity course }\end{array}$ & $\begin{array}{l}\text { Short-lecture course + } \\
\text { Internet communication } \\
\text { platform (different grades) } \\
\text { Early field experience } \\
\text { course+ Internet } \\
\text { communication platform } \\
\text { (different grades) } \\
\text { Vacation practice + Book } \\
\text { reading + Educational survey } \\
\text { Activity course + Different } \\
\text { grade +Independent design }\end{array}$ \\
\hline
\end{tabular}


(Table 2 to be continued)

\begin{tabular}{|c|c|c|c|}
\hline The practice to reflect oneself & $\begin{array}{l}\text { Daily training course } \\
\text { a } \\
\text { course } \\
\text { The presentational technology } \\
\text { teaching skill } \\
\text { Short-lecture course } \\
\quad \text { Early field experience } \\
\text { course } \\
\quad \text { Vacation practice }\end{array}$ & $\begin{array}{l}\text { Daily training course + } \\
\text { Internet communication } \\
\text { platform } \\
\text { a Educational technology } \\
\text { course+ Educational appsusing } \\
\text { a The presentation of } \\
\text { teaching skill + Design } \\
\text { micro-course online video } \\
\text { a Short-lecture course } \\
\text { +Internet communication } \\
\text { platform } \\
\text { a Early field experience } \\
\text { course+ Internet } \\
\text { communication platform } \\
\text { a Vacation practice + Book } \\
\text { studying and reading } \\
\text { activity course }\end{array}$ & $\begin{array}{l}\text { Daily training course + } \\
\text { Internet communication } \\
\text { platform } \\
\text { Educational technology } \\
\text { course + Making electronical } \\
\text { mind map } \\
\text { The presentation of } \\
\text { multiple-subject teaching skill } \\
\text { (Two class combine } \\
\text { together) } \\
\text { Thesis and book reading } \\
\text { course } \\
\text { Lecture course +Internet } \\
\text { communication platform } \\
\text { (different grades) } \\
\square \quad \text { Early field experience } \\
\text { course + Internet } \\
\text { communication platform } \\
\text { (different grades) } \\
\square \quad \text { Vacation practice + Book } \\
\text { reading + Educational survey } \\
\square \quad \text { Activity course + Different } \\
\text { grade + Independent design }\end{array}$ \\
\hline
\end{tabular}

\section{Conclusions}

Rudimentary findings from the qualitative survey showed that:

\section{The Reform of Culture Through Practice}

This study redefined the "practice" and the relationship between theory and practice. The circulation between three action round means theory learning and practice acquiring is related together. All the courses in this training system seemly pointed to promoting the educational practical ability, actually, the lasting pursuit is to find the theoretical framework and then renovate the practice.

\section{The Reform of Culture Through Learning}

This study points out that learning to students but also to teachers. Learning culture is about rebuilding the significance and relationship's students cannot cooperate with others, cannot recognize the deep learning and the surface learning, and cannot become the educator for himself/herself, they will not become a good teacher in the future. According to the reformation of learning culture, group member finds that the learning community is really a good way to achieve mutual learning and joint development.

\section{The Reform of Culture in Organizations}

This study shows students learning method, thinking method, and behavior will influence others and even the whole concept of organization. As a result, the reformation of learning and education will make a student know the most valuable thing is not the knowledge but the way to think and communicate with others, especially people's lifestyle and these things may change the culture of an organization.

\section{The Reform of Culture by Assessment}

This study changed the assessment method form summative assessment to process assessment. The whole training system contains its own index to evaluate students' performance. Compared with the score or the skill, this study pays more attention to students' confidence, willpower, motivation, courage, and ability to 
communicate, even for the pre-service teacher, the generous heart and supportive personality are really precious.

\section{The Reform of Culture Through Management}

From the beginning of this study, the research team gathered the professors from eight different departments to rebuild the teaching staff. During the study, group member rethinks the real connotation of multiple-subject teacher, design more and more activities, make them become the formal course, and join in the teaching plan of the whole university. This reformation is beginning from the bottom to top, from one course, one major to the whole school, the whole culture in management. In conclusion, the reformation of training goal and the curriculum will force the reformation of the management system in education.

From this study, group member find some new functions for education. Firstly, comprehensive reformation of education will lead the blending of national multi-culture. Secondly, this reformation also provide an opportunity to construct the civil society. Thirdly, education is belong to the political education, the cultural education and ethical education.

\section{References}

Cai, Q. T. (2005). Education action research. Nanjing: Nanjing Normal University Press.

Carr, W. (1986). Theories of theory and practice. Journal of Philosophy of Education, 20(2).

Chen, X. M. (2005). Qualitative research in social science. Beijing: Education and Science Press.

Chu, H. Q. (2016). The international perspective and China's stance of key competencies-The enhancement of national qualities and the transformation of educational goals in 21st century in China. Educational Research,38(11), 8-18.

Cohen, V. L. (2007). Federal role in teacher quality: "Redefinition” or policy alignment? Educational Policy, 19(1).

Douglas, R. M., Gary, S. B., \& Jerry, L. G. (1982). Educational psychology-An introduction. Wm.C. Brown Company Publisher.

Emans, R. (1983). Implementing the knowledge base: Redesigning the function of cooperating teachers and college supervisors. Journal of Teacher Education, 3, 14-18.

Fessler, R. \& Christensen, J. C. (2005). The teacher career teacher: Understanding and guiding the professional development of teachers. Beijing: China Light Industry Press.

Grossman, P. L., \& Richert, A. E. (1988). Unacknowledged growth: A re-examination of the effects of teacher education. Teaching and Teacher Education, 1, 53-62.

Jiang, J. F. (2016). The valuable pursue and competency characteristic of multiple-subject elementary school teachers. Journal of the Chinese Society of Education, 37(4), 80-84.

Li, Q. L., \& Chen, Y. M. (2002). The international comparison of teacher education curriculum. Beijing: Education and Science Press.

Ministry of Education, People of Republic of China. (2014, No. 5). The Suggestions about How to Carrying the Training Plan of Excellent Teacher. Beijing, China: Ministry of Education, PRC. Retrieved from http://old.moe.gov.cn//publicfiles/business/htmlfiles/moe/s7011/201408/174307.html

Ministry of Education, People of Republic of China. (2011, No. 6). The Curriculum Standards for Teacher Education (proposed). Beijing, China: Ministry of $\quad$ Education, Retrieved from http://www.moe.gov.cn/srcsite/A10/s6991/201110/t20111008_145604.html

Ministry of Education, People of Republic of China. (2001, No. 17). The Outline of National Basic Educational Curriculum Reform (proposed). Beijing, China: Ministry of Education, PRC. Retrieved from http://old.moe.gov.cn//publicfiles/business/htmlfiles/moe/s8001/201404/xxgk_167343.html

Ministry of Education, People of Republic of China. (2012, No. 1). The Curriculum Standards for Elementary School and High School Education (proposed). Beijing, China: Ministry of Education, PRC. Retrieved from http://www.moe.gov.cn/publicfiles/business/htmlfiles/moe/s7232/201212/xxgk_145603.html

Sato, M., \& Zhong, Q. Q. (2003). Curriculum and teachers. Beijing: Education and Science Press.

Shi, Z. Y. (2006). On the logic of education practice. Educational Research, 28(1), 3-9. 
Wu, Z. X., Chen, F. W., \& Zhang, Q. S. (2008, October 31). The report about researching the Japanese Akita elementary math education. Beijing Teaching and Researching Website.

Xu, H. M., \& Cao, H. Y. (2016). The analysis of connotation and training strategy of multiple-subject elementary school teachers-Based on the need of Jiangsu province. Theory and Practice of Education, 36(11), 33-35.

Zhou, D. Y. (2007). Research on curriculum system of five year training of all subjects teachers of primary schools. Journal of Educational Science of Human Normal University, 6(6), 91-95. 